\title{
Effect of selective $\beta$-adrenoceptor blockade and surgical resection of the celiac-superior mesenteric ganglion complex on delayed liquid gastric emptying induced by dipyrone, 4-aminoantipyrine, and antipyrine in rats
}

\author{
A.M. Vinagre ${ }^{1}$ and E.F. Collares ${ }^{1,2}$ \\ ${ }^{1}$ Núcleo de Medicina e Cirurgia Experimental, Faculdade de Ciências Médicas, Universidade Estadual de Campinas, \\ Campinas, SP, Brasil \\ ${ }^{2}$ Departamento de Pediatria, Faculdade de Ciências Médicas, Universidade Estadual de Campinas, Campinas, SP, Brasil
}

\begin{abstract}
There is evidence for participation of peripheral $\beta$-adrenoceptors in delayed liquid gastric emptying (GE) induced in rats by dipyrone (Dp), 4-aminoantipyrine (AA), and antipyrine (At). The present study aimed to determine whether $\beta$-adrenoceptors are involved in delayed GE induced by phenylpyrazole derivatives and the role of the prevertebral sympathetic nervous system in this condition. Male Wistar rats weighing 220-280 g were used in the study. In the first experiment rats were intravenously pretreated with vehicle $(\mathrm{V})$, atenolol $30 \mathrm{mg} / \mathrm{kg}$ (ATE, $\beta_{1}$-adrenergic antagonist), or butoxamine $25 \mathrm{mg} / \mathrm{kg}$ (BUT, $\beta_{2}$-adrenergic antagonist). In the second experiment, rats were pretreated with V or SR59230A $2 \mathrm{mg} / \mathrm{kg}$ (SRA, $\beta_{3}$-adrenergic antagonist). In the third experiment, rats were subjected to surgical resection of the celiac-superior mesenteric ganglion complex or to sham surgery. The groups were intravenously treated with saline (S), $240 \mu \mathrm{mol} / \mathrm{kg} \mathrm{Dp}, \mathrm{AA}$, or At, $15 \mathrm{~min}$ after pretreatment with the antagonists or $\mathrm{V}$ and nine days after surgery. GE was determined $10 \mathrm{~min}$ later by measuring the percentage of gastric retention (\%GR) of saline labeled with phenol red 10 min after gavage. The \%GR (means \pm SE, $n=6$ ) values indicated that BUT abolished the effect of Dp (BUT+Dp vs V + Dp: $35.0 \% \pm 5.1 \%$ vs $56.4 \% \pm 2.7 \%$ ) and At (BUT + At vs V+At: $33.5 \% \pm 4.7 \%$ vs $52.9 \%$ $\pm 2.6 \%$ ) on $\mathrm{GE}$, and significantly reduced $(\mathrm{P}<0.05)$ the effect of $\mathrm{AA}$ (BUT $+\mathrm{AA}$ vs $\mathrm{V}+\mathrm{AA}: 48.0 \% \pm 5.0 \%$ vs $65.2 \% \pm 3.8 \%$ ). ATE, SRA, and sympathectomy did not modify the effects of treatments. These results suggest that $\beta_{2}$-adrenoceptor activation occurred in delayed liquid gastric emptying induced by the phenylpyrazole derivatives dipyrone, 4-aminoantipyrine, and antipyrine. Additionally, the released neurotransmitter did not originate in the celiac-superior mesenteric ganglion complex.
\end{abstract}

Key words: Gastric emptying; Dipyrone; 4-aminoantipyrine; Antipyrine; $\beta_{2}$-Adrenoceptor; Prevertebral sympathetic ganglia

\section{Introduction}

The phenylpyrazole derivatives dipyrone, 4-aminoantipyrine, and antipyrine delay liquid gastric emptying (GE) in rats (1-3). The mechanisms involved in this process have not been clarified and appear to be complex. A previous study reported that peripheral $\beta$-adrenoceptor activation was involved in this phenomenon and suggested that sympathetic nervous system (SNS) nerve endings may release the neurotransmitter norepinephrine (4).

$\beta$-adrenoceptor subtypes have been identified along the gastrointestinal tracts of rats. $\beta_{1}$ - and $\beta_{2}$-adrenergic receptors have been detected in the mucosa and musculature of the gastric antrum, and an indeterminate subtype has been detected in the muscle tissue of the pylorus (5). Additionally, elevated $\beta_{3}$-adrenoceptor mRNA levels have been found in the muscle fibers of the gastric fundus and moderate levels have been found in the pylorus (6). $\beta_{3}$-adrenoceptors participate in the catecholamine-induced relaxation of the gastric fundus of rats in vitro (7).

Many selective $\beta$-adrenergic antagonists are available, but the affinity for these receptors appears to vary among different tissues and animal species. $\beta_{1}$-adrenoceptor antagonists are used for the control of cardiovascular diseases in humans, while $\beta_{2}$-adrenoceptor blockade results in bronchospasm (8). 
In in vivo rat models with altered gastric secretion or $\mathrm{GE}$, the selective antagonists atenolol ( $\beta_{1}$-adrenergic antagonist) (9), butoxamine ( $\beta_{2}$-adrenergic antagonist) (10), and SR59230A ( $\beta_{3}$-adrenergic antagonist) (9) have been used to identify the possible $\beta$-adrenoceptor that is involved.

SNS fibers that innervate the gastrointestinal tract mostly originate from cell bodies located in the prevertebral ganglion chain (PVG). The arrangement of the rat PVG differs from that of the other mammals (11). The PVG consists of the celiac ganglion (CG, an intimately connected pair), a single superior mesenteric ganglion (SMG), a single inferior mesenteric ganglion, a pair of splanchnic ganglia in the large splanchnic nerves, and an inter-renal ganglion located in the intermesenteric nerve between the SMG and inferior mesenteric ganglion. These ganglia are organized somatotopically in such a way that the CG and SMG project fibers to the stomach, small bowel, and proximal colon, with a large part of the fibers that innervate the stomach originating in the CG (12).

In the present study, we performed the following procedures to determine which $\beta$-adrenoceptors are involved in delayed GE induced by the phenylpyrazole derivatives dipyrone, 4-aminoantipyrine, and antipyrine, and to identify participation of the prevertebral SNS in this process in rats: i) blockade of $\beta$-adrenoceptors with the selective antagonists atenolol, butoxamine, and SR59230A, and ii) concomitant surgical resection of the celiac ganglion and the superior mesenteric ganglion.

\section{Material and Methods}

Male Wistar rats weighing 220-280 g were allowed to adapt to laboratory conditions for at least 2 weeks. The study was approved by the Ethics Committee for Animal Experimentation of the institution (protocol \#1372, CEEA/ UNICAMP).

The rats used in the study were maintained in individual cages. They had free access to food and water up to $24 \mathrm{~h}$ and 30 min before evaluation of GE between 1:00 and 4:00 pm.

Dipyrone, 4-aminoantipyrine, antipyrine, atenolol, butoxamine, SR59230A, and dimethyl sulfoxide (DMSO) were purchased from Sigma, USA. The solutions were prepared at the time of use, and when indicated, were protected from light. The doses of each drug and the method for the preparation of the solutions for intravenous (iv) use were established based on previous literature $(9-10,13)$ and tested in the laboratory in preliminary studies.

Two experiments were carried out using $\beta$-adrenergic antagonists. The first experiment involved pretreatment with selective $\beta_{1}$ - and $\beta_{2}$-adrenergic antagonists, and the rats were divided into the following groups $(n=6)$ : the ATE group, pretreated with atenolol (ATE) dissolved in vehicle $(30 \mathrm{mg} / \mathrm{kg}$ ) with a dose corresponding to 30 times the dose recommended in the literature (9); the BUT group, pretreated with butoxamine (BUT) dissolved in vehicle $(25 \mathrm{mg} / \mathrm{kg})$, corresponding to approximately three times the dose indicated in the literature (10); and the $\mathrm{V}$ group, pretreated with vehicle $(\mathrm{V})$, which was prepared with one part DMSO + four parts sterile saline (13). In the second experiment a selective $\beta_{3}$-adrenergic antagonist was tested. The rats were divided into the following groups $(n=6)$ : the SRA group, pretreated with SR59230A (SRA) $(2 \mathrm{mg} / \mathrm{kg}$ ) dissolved in vehicle, corresponding to twice the dose used for rats (9); and the $\mathrm{V}$ group pretreated with vehicle, which was prepared as described in the first study.

High doses of selective $\beta$-adrenergic antagonists were used in these pretreatments. Preliminary assessment with these doses showed that, when care was taken to slowly administer the drugs iv (30-40 s) in the most distal extremity of the rat's tail, there were no systemic repercussions that might directly compromise GE, such as agitation and respiratory difficulty observed in some animals with rapid butoxamine administration. We did not include control rats pretreated with saline. The reason for this is because a preliminary study showed that addition of DMSO to vehicle at the proportion used in relation to saline (1:4) did not interfere with GE.

In the last experiment, the rats were first subjected to surgical sympathectomy. Nine days before evaluation of $\mathrm{GE}$, these rats were sedated with $100 \mathrm{mg} / \mathrm{kg}$ ketamine and $10 \mathrm{mg} / \mathrm{kg}$ xylazine, which were administered intraperitoneally. These rats were divided into two groups as follows $(n=10)$ : rats were subjected to laparotomy with resection of the celiac-superior mesenteric ganglion complex (GLX) under a magnifying lens; and a sham group (SH) using a technique for surgical sympathectomy of the proximal part of the digestive tract of rats (14).

Fifteen minutes after pretreatment with the antagonists or the vehicle, the groups were treated iv (caudal vein) with $240 \mu \mathrm{mol} / \mathrm{kg}$ dipyrone (Dp), 4-aminoantipyrine (AA), antipyrine (At), or saline $(\mathrm{S})(1 \mathrm{~mL} / \mathrm{kg})(4)$. The same treatment was applied to the GLX and SH groups. GE was determined $10 \mathrm{~min}$ after these treatments were administered.

GE was assessed in awake animals by determining the percentage of gastric retention (\%GR) of a saline test meal that was labeled with phenol red $(60 \mu \mathrm{g} / \mathrm{mL})$, in a volume of $2 \mathrm{~mL} / 100 \mathrm{~g}$ body weight, $10 \mathrm{~min}$ after administration. The test meal was administered by gavage using a technique that was standardized in our laboratory (15), with small modifications (16).

After this procedure, the rats were sacrificed. Those of the GLX and SH groups were examined and those with intraperitoneal adhesions were excluded. Ganglionectomy was confirmed by verifying the absence of neuronal tissue at the level of the celiac and mesenteric artery branches in the exit of the abdominal aorta (14).

Data were analyzed by ANOVA and by the Tukey's test for paired comparison ( $\alpha=0.05$ for both tests).

\section{Results}

Figure 1 shows the results of iv pretreatment with ATE and BUT. Rats that were pretreated with $\mathrm{V}, \mathrm{ATE}$, or BUT and 


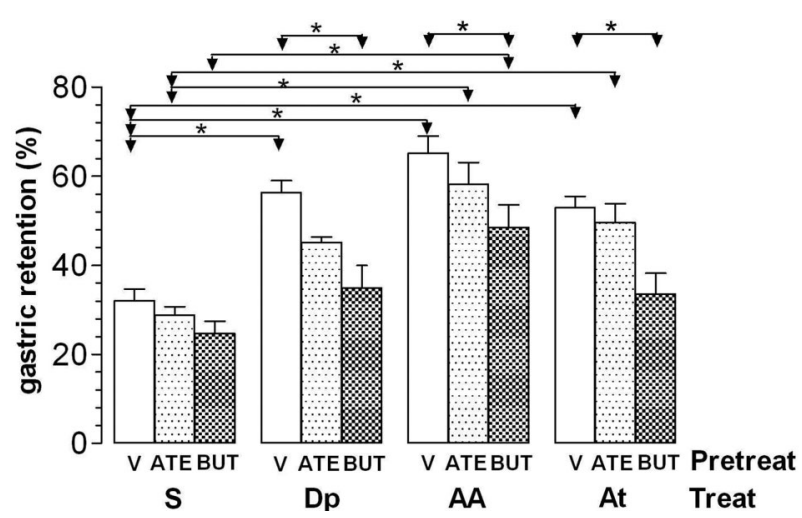

Figure 1. Gastric retention (\%) of a saline test meal provided to rats by gavage. The rats were pretreated (Pretreat) iv with vehicle (V), $30 \mathrm{mg} / \mathrm{kg}$ atenolol (ATE), or $25 \mathrm{mg} / \mathrm{kg}$ butoxamine (BUT) $15 \mathrm{~min}$ before iv treatment (Treat) with saline (S), $240 \mu \mathrm{mol} / \mathrm{kg}$ dipyrone (Dp), 4-aminoantipyrine (AA), or antipyrine (At). The test meal was administered 10 min after treatment. Data are reported as means \pm SE for 6 animals per group. ${ }^{*} P<0.05$ (Tukey's test).

treated with $\mathrm{S}$ did not show significantly different \%GR values (means $\pm S E, n=6$ ) among the groups (32.1\% $\pm 2.6 \%$, $28.8 \% \pm 1.9 \%$, and $24.7 \% \pm 2.7 \%$, respectively). Pretreatment with ATE caused no significant change in the effect of Dp $(44.9 \% \pm 1.3 \%)$, AA $(58.2 \% \pm 4.9 \%)$, or At $(49.6 \% \pm 4.2 \%)$ compared with controls pretreated with $\mathrm{V}$ and treated with the respective drugs $(56.4 \% \pm 2.7 \%, 65.2 \% \pm 3.8 \%$, and $52.9 \% \pm 2.6 \%$, respectively). The $\% G R$ in the ATE +Dp group was not significantly different from that in the ATE $+S$ group. Pretreatment with BUT abolished the effect of Dp $(35.0 \% \pm 5.1 \%)$ and At $(33.5 \% \pm 4.7 \%)$ compared with controls pretreated with $\mathrm{V}$. Pretreatment with BUT also significantly reduced $(P<0.05)$, but did not abolish, the effect of AA $(48.0 \% \pm 5.0 \%)$ compared with the $V+A A$ control.

Intravenous pretreatment with SRA (Figure 2) did not modify $\% \mathrm{GR}$ (means $\pm \mathrm{SE}, \mathrm{n}=6$ ) in rats that were treated with S $(34.5 \% \pm 3.8 \%)$ compared with controls $(26.7 \%$ $\pm 5.1 \%)$. Pretreatment with SRA also did not modify the effect of Dp $(56.5 \% \pm 7.8 \%)$, AA $(66.9 \% \pm 3.3 \%)$, and At $(57.2 \% \pm 4 \%)$ compared with rats that were pretreated with vehicle $(55.2 \% \pm 1.9 \%, 66.8 \% \pm 5 \%$, and $54.2 \% \pm 5.5 \%$, respectively).

Figure 3 shows the results of $\% G R$ (means $\pm S E, n=10$ ) in the experiment of the effect of surgical sympathectomy. Surgical resection of the celiac-superior mesenteric ganglion complex did not significantly change \%GR in rats that were treated with S compared with controls $(\mathrm{GLX}+\mathrm{S}$ vs $\mathrm{SH}+\mathrm{S}$ : $28.2 \% \pm 1.6 \%$ vs $24.9 \% \pm 1.5 \%$ ). Surgical resection of the celiac-superior mesenteric ganglion complex also did not change the effect of Dp (GLX + Dp vs SH + Dp: $46.1 \% \pm 3.3 \%$ vs $47 \% \pm 3.1 \%)$, AA (GLX+AA vs $\mathrm{SH}+\mathrm{AA}: 53.5 \% \pm 3 \%$ vs $58.6 \% \pm 3.8 \%$ ), and At (GLX+At vs SH + At: $47 \% \pm 2.9 \%$ vs $44.1 \% \pm 4 \%$ ) on $\mathrm{GE}$.

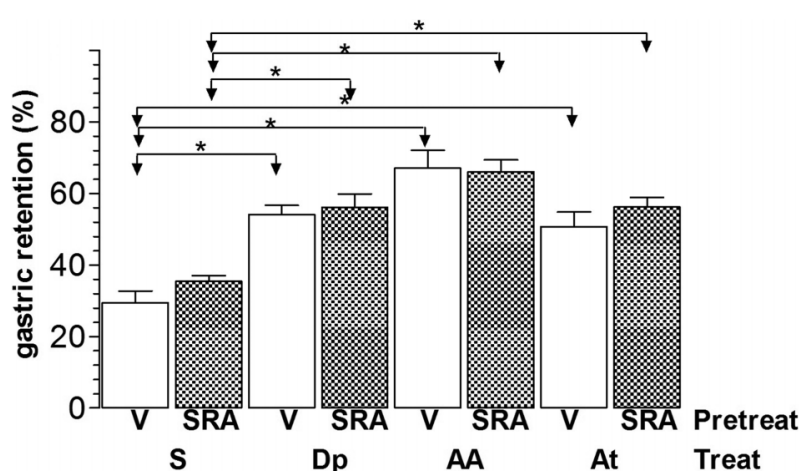

Figure 2. Gastric retention (\%) of a saline test meal provided to rats by gavage. The rats were pretreated (Pretreat) iv with vehicle (V) or with $2 \mathrm{mg} / \mathrm{kg}$ SR59230A (SRA) $15 \mathrm{~min}$ before iv treatment (Treat) with saline (S), $240 \mu \mathrm{mol} / \mathrm{kg}$ dipyrone (Dp), 4-aminoantipyrine (AA), or antipyrine (At). The test meal was administered 10 min after treatment. Data are reported as means \pm SE for 6 animals per group. ${ }^{*} \mathrm{P}<0.05$ (Tukey's test).

\section{Discussion}

In a previous study, iv pretreatment with atenolol or butoxamine at the doses of 10 and $8 \mathrm{mg} / \mathrm{kg}$ body weight, respectively, did not change the delay in liquid GE induced by dipyrone, 4-aminoantipyrine, or antipyrine in rats (Vinagre AM, personal communication). Based on this finding and evidence of participation of $\beta$-adrenoceptors in this phenomenon (4), we increased the doses of $\beta_{1}$ - and $\beta_{2}$-adreneric antagonists in our study. Additionally, previous studies have shown variation in the selectivity and affinity of the agonists and antagonists that are available for these $\beta$-receptors $(8,17)$.

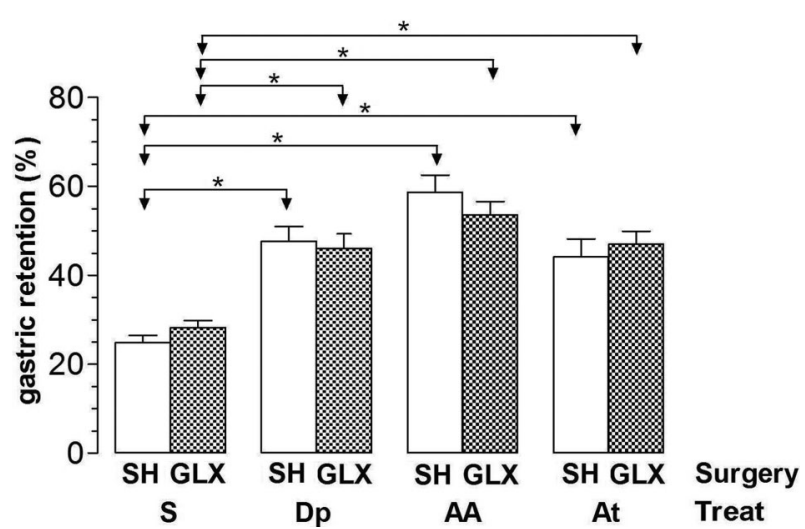

Figure 3. Gastric retention (\%) of a saline test meal provided to rats by gavage. The rats were first subjected to surgical resection of the celiac-superior mesenteric ganglion complex (GLX) or to sham surgery (SH) and treated iv (Treat) with saline (S), $240 \mu \mathrm{mol} / \mathrm{kg}$ dipyrone (Dp), 4-aminoantipyrine (AA), or antipyrine (At). The test meal was administered 10 min after treatment. Data are reported as means \pm SE for 10 animals per group. ${ }^{*} \mathrm{P}<0.05$ (Tukey's test). 
We found that butoxamine at a dose three times higher than that used in a previous study (Vinagre AM, personal communication) blocked the delay in liquid GE induced by dipyrone and antipyrine in rats and attenuated the effect of 4-aminoantipyrine (Figure 1). This finding suggests that activation of $\beta_{2}$-adrenergic receptors occurs with these drugs. These results are consistent with those observed in another study in which previous adrenergic blockade with guanethidine and pretreatment with propranolol (nonselective $\beta$-adrenergic antagonist) were studied (4).

In our study, atenolol (Figure 1) and SR59230A (Figure 2) did not significantly modify the effect of phenylpyrazole derivatives. This finding indicated unlikely activation of $\beta_{1}$ - or $\beta_{3}$-adrenergic receptors in delayed GE, which was induced by dipyrone, 4-aminoantipyrine, or antipyrine. High doses of these antagonists might compromise these interpretations because of their potential effect on the cardiovascular system when administered alone or in combination with phenylpyrazole derivatives.

In two rat models, changes in gastrointestinal motility appear to be directly related to variation in some hemodynamic parameters. In the first model, consisting of controlled bleeding, an acute decrease in arterial pressure and central venous pressure is accompanied by increased liquid GE (18). In the second model, consisting of a reduction in arterial pressure and increased venous pressure due to an aortocaval fistula, there is a delay in GE (19). These observations suggest that distinct mechanisms may be involved in different acute hemodynamic situations, with repercussions on gastric motility.

Studies on rats investigating the effects of $\beta$-adrenergic antagonists on some cardiovascular parameters have indicated the following. 1) acute atenolol administration (1 mg/kg by the peripheral intra-arterial route) significantly reduces cardiac output, heart rate, mean arterial pressure, and blood flow to the stomach and small bowel, increasing the total peripheral vascular resistance (20). 2) Thirty minutes after intraperitoneal administration of $10 \mathrm{mg} / \mathrm{kg}$ butoxamine, there is no change in heart rate or mean arterial pressure compared with basal values (21). 3) SR59230A alone, $1 \mathrm{mg} / \mathrm{kg} \mathrm{i}$, does not modify mean arterial pressure or cardiac output in animals with liver cirrhosis (22). Therefore, among these $\beta$-adrenergic antagonists, atenolol has the greatest effect on the cardiovascular system. This suggests that, in the present study, use of atenolol at a 30 times higher dose than that demonstrating an effect on the cardiovascular system (20) may have had a greater effect on this system.

We did not find that increasing $\beta$-blocker doses alone modified liquid GE in rats. In the present study, the lack of a significant difference in \%GR between control animals pretreated with vehicle or $\beta$-blockers and rats treated with saline (Figures 1 and 2) indicates that it is unlikely that these antagonists interfered per se with liquid GE.
Among humans, approximately $0.4 \%$ of patients who received dipyrone parenterally showed a significant reduction in systolic arterial pressure as an adverse effect (23). A single iv dose of $2 \mathrm{~g}$ dipyrone reduced the postoperative left ventricular work index by $10 \%$ in patients who had heart surgery (24). Because these changes were detected in patients with some health problems, other factors alone or in combination with this drug might be responsible for these phenomena.

In our laboratory, mean arterial pressure was measured in the left carotid artery of sedated rats $(n=5-6)$ over $30 \mathrm{~min}$ after iv administration of vehicle (saline), $240 \mu \mathrm{mol} / \mathrm{kg}$ dipyrone, 4-aminoantipyrine, or antipyrine (Passafaro ACD, personal communication). Arterial pressure remained at similar levels to those measured initially (time 0) for up to $10 \mathrm{~min}$ after administration of these drugs in treated rats. This was followed by a discrete and gradual decrease in arterial pressure compared with controls and initial values. At 30 min after administration, the difference in arterial pressure between the groups was not significant $(P<0.08$, ANOVA, $\alpha=0.05)$. In the current study, we did not assess the hemodynamic condition of the rats. However, even if the combination of atenolol and pyrazolone derivatives substantially reduced arterial pressure, this did not interfere with the effect of treatment of the three drugs on GE (Figure 1). Therefore, there is no evidence that pretreatment with high doses of $\beta$-adrenergic antagonists, atenolol in particular, compromised our results because of their effect on the cardiovascular system.

The method of selective SNS surgery was used in our study to determine the origin of the neurotransmitter. This procedure is recommended for assessment of participation of this system in phenomena observed in a target organ (25). We simultaneously performed surgical resection of the CG and MSG, ganglia from which efferent fibers are projected towards the proximal part of the digestive tract of the rat $(12,14)$. The results of this procedure (Figure 3 ) suggested that these structures were not involved in the delay in GE, which was induced by phenylpyrazole derivatives.

There are at least three other possibilities that may explain the origin of the neurotransmitter from the SNS. The first possibility is that our results do not exclude participation of the PVG in the effect of dipyrone, 4-aminoantipyrine, or antipyrine because the procedure did not involve removal of the pair of splanchnic ganglia that contain neurons, which together with those of the CG and SMG, innervate the gastrointestinal tract (12). The second possibility is that the involved neurotransmitter may originate from fibers of the sympathetic paravertebral ganglion chain for the distal part of the thorax. These fibers project towards the stomach and duodenum (12). Finally, the neurotransmitter may originate in the noradrenergic efferent fibers of the vagus nerve (26-28). Although there is no strong evidence of occurrence of these fibers, this possibility is supported by the fact that subdiaphragmatic vagotomy abolishes or reduces the 
effect of studied drugs (1-3). However, this possibility is not as likely if we consider that vagotomy also results in the incision of capsaicin-sensitive afferent fibers, which are involved in the effect of dipyrone, 4-aminoantipyrine, or antipyrine on GE in rats (16).

\section{References}

1. Collares EF, Vinagre AM. Evidence of the effect of dipyrone on the central nervous system as a determinant of delayed gastric emptying observed in rats after its administration. Braz J Med Biol Res 2003; 36: 1375-1382, doi: 10.1590/ S0100-879X2003001000014.

2. Soares AC, Vinagre AM, Collares EF. Effect of antipyrine on the gastric emptying of liquid in rats. Braz J Med Biol Res 2006; 39: 1507-1512, doi: 10.1590/S0100-879X2006001100015.

3. Vinagre AM, Collares EF. Effect of 4-aminoantipyrine on gastric compliance and liquid emptying in rats. Braz J Med Biol Res 2007; 40: 903-909, doi: 10.1590/S0100-879X2006005000119.

4. Vinagre AM, Collares EF. Evidence for the involvement of peripheral beta-adrenoceptors in delayed liquid gastric emptying induced by dipyrone, 4-aminoantipyrine, and antipyrine in rats. Braz J Med Biol Res 2013; 46: 735-738, doi: 10.1590/ 1414-431X20132975.

5. Yu O, Ouyang A. Distribution of beta-adrenoceptor subtypes in gastrointestinal tract of nondiabetic and diabetic BB rats. A longitudinal study. Dig Dis Sci 1997; 42: 1146-1153, doi: 10.1023/A:1018877318101.

6. Evans BA, Papaioannou M, Bonazzi VR, Summers RJ. Expression of beta 3-adrenoceptor mRNA in rat tissues. Br J Pharmacol 1996; 117: 210-216, doi: 10.1111/j.14765381.1996.tb15176.x.

7. Ozakca I, Arioglu E, Guner S, Altan VM, Ozcelikay AT. Role of beta-3-adrenoceptor in catecholamine-induced relaxations in gastric fundus from control and diabetic rats. Pharmacology 2007; 80: 227-238, doi: 10.1159/000104876.

8. Baker JG. The selectivity of beta-adrenoceptor antagonists at the human beta1, beta2 and 3 adrenoceptors. Br J Pharmacol 2005; 144: 317-322, doi: 10.1038/sj.bjp.0706048.

9. Tsukada F, Nagura Y, Abe S, Sato N, Ohkubo Y. Effect of restraint and footshock stress and norepinephrine treatment on gastric emptying in rats. Biol Pharm Bull 2003; 26: 368-370, doi: 10.1248/bpb.26.368.

10. Canfield SP, Price CA. A comparison of the effects of sympathomimetic agents on gastric acid secretion by the rat stomach in vivo and in vitro. J Physiol 1981; 316: 11-21, doi: 10.1113/jphysiol.1981.sp013768.

11. Szurszewski JH, Linden DR. Physiology of prevertebral sympathetic ganglia. In: Johnson LR (Editor), Physiology of the gastrointestinal tract. 5th edn. USA: Elsevier Inc.; 2012. p. 583-627, doi: 10.1016/B978-0-12-382026-6.00020-8.

12. Quinson N, Robbins HL, Clark MJ, Furness JB. Locations and innervation of cell bodies of sympathetic neurons projecting to the gastrointestinal tract in the rat. Arch Histol Cytol 2001; 64: 281-294, doi: 10.1679/aohc.64.281.

\section{Acknowledgments}

The research was supported by Fundo de Apoio ao Ensino, à Pesquisa e Extensão (FAEPEX), Universidade Estadual de Campinas (UNICAMP), Campinas, SP, Brasil.

13. Nackley AG, Tan KS, Fecho K, Flood P, Diatchenko L, Maixner W. Catechol-O-methyltransferase inhibition increases pain sensitivity through activation of both beta2- and beta3adrenergic receptors. Pain 2007; 128: 199-208, doi: 10.1016/ j.pain.2006.09.022.

14. Fu J, Dipatrizio NV, Guijarro A, Schwartz GJ, Li X, Gaetani $S$, et al. Sympathetic activity controls fat-induced oleoylethanolamide signaling in small intestine. $J$ Neurosci 2011; 31: 5730-5736, doi: 10.1523/JNEUROSCI.5668-10. 2011.

15. Bucaretchi F, Collares EF. Effect of Phoneutria nigriventer spider venom on gastric emptying in rats. Braz J Med Biol Res 1996; 29: 205-211.

16. Vinagre AM, Collares EF. Phenylpyrazolone derivatives inhibit gastric emptying in rats by a capsaicin-sensitive afferent pathway. Braz J Med Biol Res 2009; 42: 1086-1089, doi: 10.1590/S0100-879X2009001100014.

17. Arch JR. Do low-affinity states of beta-adrenoceptors have roles in physiology and medicine? Br J Pharmacol 2004; 143: 517-518, doi: 10.1038/sj.bjp.0705991.

18. Gondim FA, de-Oliveira GR, Graca JR, Cavalcante DI, Souza MA, Santos AA, et al. Variations in gastric emptying of liquid elicited by acute blood volume changes in awake rats. Braz J Med Biol Res 1998; 31: 967-973, doi: 10.1590/ S0100-879X1998000700013.

19. Silva MT, Palheta RC Jr, Oliveira FG, de Lima JB, AntunesRodrigues J, Oliveira RB, et al. Aortocaval fistula delays gastric emptying of liquid test meal in awake rats. Am J Physiol Heart Circ Physiol 2013; 304: H1397-H1405, doi: 10.1152/ajpheart.00827.2012.

20. Risberg J, Hordnes C, Tyssebotn I. The effect of beta 1adrenoceptor blockade on cardiac output and organ blood flow in conscious rats. Scand J Clin Lab Invest 1987; 47: 521-527, doi: 10.1080/00365518709168463.

21. Zlotnik A, Klin Y, Gruenbaum BF, Gruenbaum SE, Ohayon S, Leibowitz $A$, et al. beta2 adrenergic-mediated reduction of blood glutamate levels and improved neurological outcome after traumatic brain injury in rats. J Neurosurg Anesthesiol 2012; 24: 30-38, doi: 10.1097/ANA.0b013e318232deaa.

22. Vasina V, Giannone F, Domenicali M, Latorre R, Berzigotti A, Caraceni $P$, et al. Portal hypertension and liver cirrhosis in rats: effect of the beta3-adrenoceptor agonist SR58611A. Br J Pharmacol 2012; 167: 1137-1147, doi: 10.1111/j.14765381.2012.02074.x

23. Hoigne R, Zoppi M, Sollberger J, Hess T, Fritschy D. Fall in systolic blood pressure due to metamizol (dipyrone, noramidopyrine, novaminsulfone). Results from the Comprehensive 
Hospital Drug Monitoring Berne (CHDMB). Agents Actions Suppl 1986; 19: 189-195.

24. Avellaneda C, Gomez A, Martos F, Rubio M, Sarmiento J, de la Cuesta FS. The effect of a single intravenous dose of metamizol $2 \mathrm{~g}$, ketorolac $30 \mathrm{mg}$ and propacetamol $1 \mathrm{~g}$ on haemodynamic parameters and postoperative pain after heart surgery. Eur $J$ Anaesthesiol 2000; 17: 85-90.

25. Picklo MJ. Methods of sympathetic degeneration and alteration. J Auton Nerv Syst 1997; 62: 111-125, doi: 10.1016/S0165-1838 (96)00121-X.
26. Willing AE, Berthoud HR. Gastric distension-induced c-fos expression in catecholaminergic neurons of rat dorsal vagal complex. Am J Physiol 1997; 272: R59-R67.

27. Yang M, Zhao X, Miselis RR. The origin of catecholaminergic nerve fibers in the subdiaphragmatic vagus nerve of rat. J Auton Nerv Syst 1999; 76: 108-117, doi: 10.1016/S01651838(99)00014-4.

28. Guo JJ, Browning KN, Rogers RC, Travagli RA. Catecholaminergic neurons in rat dorsal motor nucleus of vagus project selectively to gastric corpus. Am J Physiol Gastrointest Liver Physiol 2001; 280: G361-G367. 